\title{
The OTC global derivatives markets: An expositional analysis
}

\section{Themis D. Pantos}

Accounting and Finance Department, College of Business, San Jose State University, One Washington Square, San Jose, CA 95192-0066, USA.

Tel: + 1408924 3472, Fax: + 1408924 3463, E-mail: pantos_t@cob.sjsu.edu

Received (in revised form): 3rd May, 2007

Themis D. Pantos is Professor of Finance in the Department of Accounting and Finance, College of Business, at the San Jose State University, California, USA. He received his PhD in Finance from the Joseph L. Rotman School of Management, University of Toronto, Canada, his MA in Economics from York University, Downsview, Ontario, Canada and his BBA from the Graduate Industrial School of Thessaloniki, Thessaloniki, Greece respectively. He has published numerous articles in various peer-reviewed finance, taxation, and economics journals. Dr Pantos' research and teaching interests are in the areas of Capital Markets and Institutions, International Finance and Derivative Securities, and he is the winner of the College of Business Research Award (2007) and a holder of the Lucas Research Fellowship for the academic years (2007, 2006), respectively. He has also won several Academic California State University Research Awards and is the winner of the Outstanding Faculty Award (2007), from the Disability Resource Center, and a holder of the prestigious Outstanding Undergraduate Professor Teaching Award (2004), at the San Jose State University. He was nominated for the President Teaching/Scholar Award at San Jose State University in 2006 and 2002 respectively and has also won 'The MBA Faculty Choice Award' in 2000, at Rutgers University, Camden, New Jersey.

\section{Abstract}

Emm and Gay (2005) have put forward an academic paper that merits a response because of its own strength and the misunderstandings of the economic and risk implications of the existence of high concentration ratios in the OTC dealer derivatives markets. This study suggests that their analysis is incorrect. In addition, this paper states that high dealer concentration ratios in the OTC financial markets do not indicate derivative markets that are not competitive and vulnerable to the financial sector weaknesses.

Journal of Derivatives \& Hedge Funds (2008) 13, 305-310. doi:10.1057/palgrave.jdhf.1850080

\& Hedge Funds, Vol. 13 No. 4, 2008, pp. $305-310$ (C) 2008 Palgrave Macmillan Ltd $1753-9641 \$ 30.00$
Keywords: dealer concentration ratios; derivative markets risk; systemic risk

\section{INTRODUCTION}

A financial system is defined by a set of intermediaries through which households, corporations, and sovereign governments obtain funding for their economic activities, invest their savings, and transfer the various kinds of risk among themselves. In a given financial system, the mixture of financial markets and intermediaries operating in the economy defines what is known in the standard economic textbook theory as the financial structure of the system. ${ }^{1}$

The Over-the-Counter (hereafter, OTC) financial dealer derivatives markets are playing a significant role in fulfilling the above-mentioned economic goals. Smooth functioning, fully integrated, efficient, and liquid OTC dealer 
derivatives markets not only transfer and hedge risk among the various market participants but also minimise it and hence create a net positive effect for the whole domestic and global economy, respectively.

In the winter issue of the Journal of Futures Markets, Ekaterina E. Emm and Gerald D.Gay ${ }^{2}$ presented their academic views on the analysis of dealer holdings on the global market for overthe-counter (hereinafter, referred to as OTC) derivatives markets. Their writing style was sharp and penetrating and their thoughts were provoking and well articulated. They wrote with insight and wit, claiming in their descriptive academic research that the OTC derivative dealer concentration ratios have substantially increased both in the US and in the global markets over the period 1995-2001.

Emm and $\mathrm{Gay}^{2}$ have put forward an academic paper that merits a response because of its own strength and the misunderstandings of the economic and risk implications of the existence of high concentration ratios in the OTC dealer derivatives markets. There is not much in their research analysis that I agree with. Indeed, to understand our disagreement, it is necessary first to recognise the extent of our common ground.

I agree with the authors' remarks that the OTC global and domestic dealer derivatives markets are highly concentrated. I disagree, however, with their analysis in three distinct ways. First, concentration ratios in the OTC dealer derivatives markets cannot be computed by using global market share percentages. Standard textbook industrial organisation and regulatory finance theory suggests that this particular computational method could not yield valid and testable economic conclusions.

The concentration statistics that are used for computational purposes and testable economic implications in the modern industrial organisation and regulatory finance fields constitute the following prime indices: (1) The Hirschman-Herfindahl Index, (2) The Entropy Index, (3) The Lorenz Curve and the Gini Coefficient Index, (4) The Hannah-Kay Index, (5) The Rosenbluth Index, and (6) The Inverse of the Concentration Ratio Index. ${ }^{3}$

Secondly, high concentration ratios in the OTC dealer derivatives markets do not indicate markets that are not competitive. Lastly, high concentration statistics neither increase systemic risk nor create the following three interrelated problems: (i) financial sector weakness,

(ii) contagion or domino market effects, and

(iii) reassessment of dealers' and investors' credit worthiness.

The paper proceeds as follows: The next section introduces and highlights their main arguments for the existence of high dealer concentration ratios in the OTC derivatives markets and the effects on the systemic risk. The subsequent section offers my own analysis and critique on their study. The final section concludes.

\section{EMM AND GAY'S ${ }^{2}$ THESIS}

Emm and $\mathrm{Gay}^{2}$ claim in their research that the OTC derivatives markets dealer concentration ratios have substantially increased both in the domestic and the global economic environment over the period 1995-2001. According to them, these particular markets constitute the supply side of financial intermediation and arose primarily because of the need of the various firm requirements for managing and hedging the elements of financial risk.

They analyse derivative holdings of 264 dealers dispersed over 34 sovereign countries by 
utilising a specific, in terms of the uniqueness longitudinal database from the Swaps Monitor Publications Inc., and computed levels and trends of dealer concentration for both the global and the domestic US derivatives markets by using global market share percentages. In their findings, the authors indicate [first paragraph, p. 42] that:

'[... On both levels, dealer concentration has grown significantly over our sample period.

For example, the 4 and 20 firm concentration ratios for the global population of dealers have risen from $14 \%$ to $28 \%$ and $48 \%$ to $67 \%$, respectively. In the United States, the statistics are even higher, with ratios having risen to $69 \%$ and $98 \%$ respectively. We briefly discuss potential concerns that these statistics may suggest regarding systemic risk in the financial system. We also analyze the extent of global merger activity that has occurred among derivatives dealers and discuss various effects on industry structure.]'

Proceeding with their analysis, the authors discuss the statistics for the years 1995 and 2000, respectively, and present their results graphically in Figure 1. They maintain [second paragraph, p. 52] that:

'[As we observe in Figure 1, for both samples the levels of concentrations have grown significantly over the years as indicated by the upward shift in the two sets of curves. To illustrate, for the global sample of dealers (see the GL'95 and GL'00 curves) in 1995 the four-firm ratio was $14 \%$, the eight-firm ratio was $23 \%$, and the $20-$ firm ratio was $48 \%$. In 2000 these percentages had grown to $28 \%$, $42 \%$, and $67 \%$, respectively. For U.S. dealers, concentration levels (see U.S'95 and U.S.'00) are significantly higher than those measured on a global basis and have also increased over time. In 1995 the four-firm U.S. concentration ratio was $45 \%$, the eight-firm ratio was $70 \%$, and the 20 -firm ratio was $98 \%$. By 2000 these had grown to $69 \%, 89 \%$, and 98\% respectively.]'

The authors asserted [first paragraph, p. 53] that:

'[Although the concentration numbers just presented appear high, we present them solely as another indicator of industry structure. We acknowledge that a number of concerns have been expressed by policy makers and market observers with respect to the growth and size of the derivatives market and level of concentration therein. Many of these have centered on systematic risk concerns, that is, the risk that a default by a major dealer could cause a domino effect, affecting not only the well-being of immediate counterparties, but spreading and ultimately threatening the entire system. However, we note the number of safeguards in place to help prevent such occurrences including regulatory initiatives, such as bank examinations and capital adequacy standards.]'

The authors stated [first paragraph, p. 54] that:

'[...More important, the dealer community has been proactive in making important advances with the development and use of master agreements, collateral agreements, and other risk-mitigation arrangements. For further discussion of these market-based mechanisms for addressing counterparty risk, 
see, for example, the Group of Thirty (1993), Gay and Medero (1996), and Weinstein (2003). Also, Bomfim (2002) finds empirical evidence that netting agreements and other credit enhancement mechanisms used in swaps markets have been successful in mitigating counterparty credit risk during periods of market turmoil.]'

Finally, the authors concluded [last paragraph, p. 66] that:

'[We conclude by noting that studies such as this should provide additional guidance, and to some extent restraint, to policy makers and other market observers who have expressed concerns over the growing size of this market. Certainly, additional analysis regarding levels of credit exposure and replacement values of positions held by dealers are logical extensions of the work presented here. Further, analysis of the degree to which increasing product line diversification may ameliorate systematic risk concerns would be beneficial. Still, we share the belief that the growth of the global economy has been and will continue to be greatly assisted by the wide availability of OTC derivative products that enable participants to better manage risks.]'

\section{ANALYSIS AND CRITIQUE OF EMM AND GAY'S ${ }^{2}$ STUDY}

The first part of my critique is based on the concentration statistics that the authors should have used to compute correctly the concentration ratios for the domestic and the global OTC dealers for the derivatives markets, respectively. They should have used specifically the global and the US national markets and a three or four Digit Standard Industry Classification System (hereafter, DSICS) computing the following prime concentration indices: (1) The Hirschman-Herfindahl Index and its Variance, (2) The Entropy Index, (3) The Lorenz Curve and the Gini Coefficient Index, (4) The Hannah-Kay Index, (5) The Rosenbluth Index, and (6) The Inverse of the Concentration Ratio Index. ${ }^{4}$

Instead, the authors have computed levels and trends of dealer concentration for both the global and the domestic US derivatives markets by using global market share percentages. In their incorrect findings, the authors have asserted [first paragraph, p. 53] that:

'[...Although the concentration numbers just presented appear high, we present them solely as another indicator of industry structure. We acknowledge that a number of concerns have been expressed by policy makers and market observers with respect to the growth and size of the derivatives market and level of concentration therein. Many of these have centered on systematic risk concerns, that is, the risk that a default by a major dealer could cause a domino effect, affecting not only the well-being of immediate counterparties, but spreading and ultimately threatening the entire system. However, we note the number of safeguards in place to help prevent such occurrences including regulatory initiatives, such as bank examinations and capital adequacy standards.]'

Their statement is not only invalid but can also be misleading. You cannot under any circumstances examine an industry structure measuring the extent of competition and claim that you present such high concentration ratios 
only as indicators of the industry structure, especially when your results should be inversely related to market power, which is the ability of the dealers in the OTC industry to influence the price of their product based on the extent of competition and elements of systemic risk.

The second part of my critique is based on Fama and Laffer's ${ }^{5}$ economic argument with respect to the existence of high levels of concentration ratios in dealers and assets markets. The authors concluded that a high concentration can be consistent with competitive markets that display no financial sector susceptibility as long as the dominant leader firms or dealer does not exercise any market power. If a dominant firm or a dealer exercises any market power, then standard textbook industrial organisation theory suggests that the firm/dealer would have earned excessive amount of profits in the OTC derivatives markets.

Then the fundamental question that Emm and Gay's ${ }^{2}$ study should have posed is: Did the 'leading global and domestic US dealers', as they presented in Table 3 of their paper, earn excessive profits? The well-documented evidence from their paper and all previous academic studies concluded against any measure of market power exercised from any dominant global or US dealer and against any amount of excessive profits earned in the OTC derivatives markets.

Thus, the OTC financial derivatives markets are highly contestable and competitive and therefore the prices of dealers services are strictly determined directly from costs since no price discrimination or any high barriers to entry and exit exist in these markets. Moreover, the mere existence of the so-called 'arm-length transactions' model where no 'relationship-ties' occur among the various players of the OTC dealer derivatives markets for financial services assures that perfect competitive conditions hold and satisfy the price equal to the marginal cost condition.

The third part of my critique is based on the element of the systemic risk. Any OTC financial sector weaknesses stem from inherited longstanding problems (eg, the various derivatives scandals) in the OTC dealer derivatives markets. These long-standing problems or inherited weaknesses cannot be cured by the existence of a heavy regulatory framework in the OTC dealer derivatives markets as the authors suggested in their paper.

For instance, Emm and $\mathrm{Gay}^{2}$ maintain [first paragraph on p. 54] that:

'[...However, we note the number of safeguards in place to help prevent such occurrences including regulatory initiatives, such as bank examinations and capital adequacy standards.]'

Again, their statement is inaccurate and partially misleading. The 'reason d' etré' is that too much 'policy-directed' regulatory-initiatives with respect to the OTC dealer examinations regarding their core capital adequacy standards, topped by strong expectations of government bailout in case of a financial emergency, will eventually lead to the creation of the so-called 'moral-hazard' problem and the subsequent eruption of a heavy economic crisis in the OTC dealers derivatives markets.

As long as these markets operate under the principles of the Anglo-American model that emphasises 'arm-length' market relationships and there exist no deep flaws in the financial infrastructure of the OTC dealer derivatives markets due to excessive leverage, or 'relationship-lending', these markets will clear and be perfectly competitive. These particular 
markets do not need a heavy regulatory environment to function properly. By installing a 'mere-figure' heavy regulatory framework, you provide primarily a false sense of security with unnecessary and costly insurance schemes and secondarily you set the stage for a financial crisis to occur because of the existence of the 'moral-hazard' problem.

If economic agents will be bailed out even under the worst circumstances and the OTC dealer has too little of its own capital at stake, the dealer may have an incentive to take excessive risks. If the risks pay off, the dealer keeps the profits. If not, the government bails out the economic agents or the counterparties. At this point you need monitoring in order to prevent the OTC dealers of derivatives markets from taking undue risks. If 'prudential regulations' do not succeed to prevent dealers of the OTC derivatives markets from taking undue risks, a contagion effect will be created.

This will act as a 'wake-up call' for the global and the domestic investor in order to reassess the creditworthiness of the OTC dealer derivatives markets. The outcome of a contagion is a 'self-fulfilling' prophecy. If every economic agent forms beliefs that the dealers of the OTC derivatives markets are economically sound and their reserves will be sufficient to meet any liquidity demands that might arise in the event of a financial crisis, then equilibrium will automatically be restored and OTC markets will clear. If not, the dealer will go under and a sequential catastrophic run will follow. The simple solution to this problem is to create a 'lender of the last resort' or an OTC type of an 'insurance-agency' that can step in as 'deus-ex-machina' to provide the necessary financial assistance in case of a run and save the
OTC dealers from any illiquidity or insolvency problems.

\section{CONCLUSIONS}

Emm and Gay ${ }^{2}$ have put forward an academic paper that merits a response because of its own strength and the misunderstandings of the economic and risk implications of the existence of high concentration ratios in the OTC dealer derivatives markets. In this paper, I have attempted to address and eventually shed some light on the three distinct and controversial issues that arose in their paper. This study contributes to our understanding of the rationale for the existence of high dealer concentration ratios in the OTC dealer derivatives markets and claims that we can have competitive OTC dealer derivatives markets even in the presence of high dealer concentration ratios without increasing the elements of systemic risk domestically or globally.

\section{Acknowledgments}

I would like to express my sincere thanks to Michael Solt and Janis Zaima for helpful comments and suggestions. The usual disclaimer applies.

\section{References and Notes}

1 For instance, see Pantos, T.D. (2004) 'The Canadian Keiretsu: Myth or Reality', Journal of Banking Regulation, Vol. 5, No. 3, pp. 251-255.

2 For more on this, see Emm, E.E. and Gay, G.D. (2005) 'The Global Market for OTC Derivatives: An Analysis of Dealer Holdings', Journal of Futures Markets, Vol. 25, No. 1, pp. 39-77.

3 For a detailed analysis, see for instance, Bruner, R.F. (2004) 'Applied Mergers and Acquisitions', 1st edn. John Wiley \& Sons, Inc., Hoboken, NJ, USA.

4 For more on this, see Green, C. (1990) 'Canadian Industrial Organization and Policy’, 3rd edn. McGrawHill, Ryerson Limited, Toronto, Ontario, Canada.

5 Fama, E. and Laffer, A. (1972) 'The Number of Firms and Competition', American Economic Review, Vol. 62, No. 4, pp. 670-674. 